\title{
A Bioengenharia tecidual em favor da reabilitação de indivíduos com fissura labiopalatina
}

\section{The tissue Bioengineering in favor of the rehabilitation of individuals with cleft lip and palate}

\author{
Marcos R. T. Palone', Thaieny R. da Silva², Gisele da S. Dalben ${ }^{3}$
}

\begin{abstract}
RESUMO
A Bioengenharia tecidual compila conhecimentos de grandes áreas da ciência, os quais são aplicados atualmente em tratamentos de saúde com finalidade reparadora. No HRAC/USP pacientes com fissura labiopalatina são atualmente reabilitados com uso da rhBMP-2. Diante disso, o objetivo do presente estudo foi realizar um trabalho de revisão e atualização enfatizando as características principais da rhBMP-2. O tratamento com este biomaterial tem mostrado taxas de sucesso semelhantes às do tratamento convencional obtido de osso ilíaco para este grupo de pacientes, bem como vantagens adicionais. O conhecimento sobre suas aplicações e cuidados necessários é de grande valia para profissionais e acadêmicos da área de Ciências Biológicas e da Saúde durante o seu processo de formação universitária.
\end{abstract}

Palavras-chave: Bioengenharia, Enxerto, Cirurgia.

\begin{abstract}
Tissue Bioengineering involves knowledge of several science fields, which are currently employed in reparative health treatments. At HRAC/USP, individuals with cleft lip and palate are currently rehabilitated with the use of rhBMP-2. This paper aims to present a review and update with emphasis on the main characteristics of rhBMP-2. The treatment with this biomaterial has demonstrated similar success rates as the conventional treatment obtained from the iliac bone for this group of individuals, as well as additional advantages. Knowledge on its applications and the necessary care is very important for professionals and students in the fields of Biological and Health Sciences during the university training.
\end{abstract}

Keywords: Bioengineering, Graft, Surgery.

1. Especialista em Odontopediatria, Mestrando em Ciências da Reabilitação no Hospital de Reabilitação de Anomalias Craniofaciais da Universidade de São Paulo, Bauru, Brasil.

2. Especialista em Odontopediatria, Mestra em Ciências da Reabilitação, Doutoranda em Ciências da Reabilitação no Hospital de Reabilitação de Anomalias Craniofaciais da Universidade de São Paulo, Bauru, Brasil.

3. Especialista em Odontopediatria, Mestra em Ciências da Reabilitação, Doutora em Patologia Bucal, Cirurgiã-dentista do Hospital de Reabilitação de Anomalias Craniofaciais da Universidade de São Paulo, Bauru, Brasil.
Correspondência: Marcos Roberto Tovani Palone Seção de Odontopediatria e Saúde Coletiva Rua Silvio Marchione, 3-20 - Vila Universitária CEP 17012-900 - Bauru - SP marcos_palone@ hotmail.com

Artigo recebido em 11/03/2014 Aprovado para publicação em 07/07/2014 


\section{Introdução}

A Bioengenharia tecidual consiste em uma área recente de pesquisa multidisciplinar que contempla conhecimentos de grandes áreas da ciência, como a biologia e a engenharia, a qual promove o desenvolvimento e manipulação de implantes artificiais, de tecidos gerados em laboratório e/ou de células ou moléculas capazes de substituir ou estimular funcionalmente partes danificadas do nosso organismo de maneira reparadora a fim de recriar tecidos funcionais e órgãos saudáveis. ${ }^{1}$

Um enxerto ósseo de sucesso está associado a três processos diferentes: osteogênese, osteoindução e osteocondução. As células osteogênicas estimulam a formação óssea em tecidos moles ou aceleram o crescimento ósseo nos próprios sítios ósseos. A osteoindução representa a capacidade de um material de formar osso em uma região onde nenhum osso iria se formar. A osteocondução seria a propriedade apresentada pelos materiais de manter um arcabouço de forma a permitir a migração de células ósseas ou mesmo mesenquimais indiferenciadas para o interior do defeito e dessa forma contribuir para a neoformação óssea. ${ }^{2}$

As proteínas morfogenéticas ósseas (bone morphogenetic proteins-BMP) fazem parte da superfamília de fatores de crescimento (TGF- $\beta$ ) e estão envolvidas nos processos de desenvolvimento embriológico e da formação do esqueleto. De acordo com Urist $(1965)^{3}$ e Urist e Strates (1971) ${ }^{4}$, estes agentes foram identificados mediante extensa pesquisa laboratorial, denominando-os BMPs. Foi demonstrado com estes trabalhos que, ao colocar porções de matriz óssea alogênica desmineralizada e liofilizada na musculatura de coelhos, ocorre formação óssea (Figura 1: A, B e C). ${ }^{3,4,5}$
Diante disso, o objetivo do presente estudo foi realizar um trabalho de revisão e atualização enfatizando as características principais da rhBMP-2.

\section{Revisão de literatura}

\section{rhBMP-2 e a fissura labiopalatina}

A molécula de rhBMP-2, proteína morfogenética óssea recombinante humana, quando colocada em meio adequado induz formação óssea (Figura 2). O início do processo não se faz necessariamente pela introdução de células que formam osso. Ao contrário, a rhBMP-2 age localmente para concentrar as células mesenquimais hospedeiras ali e influenciar sua diferenciação em células formadoras de tecido ósseo (osteoblastos). Ela tem atividade mitogênica, mas esta é seletiva. ${ }^{6}$ Para que se tenha um efeito que possa ser observado clinicamente são necessárias doses superfisiológicas, algo em torno de 200.000 vezes a concentração fisiológica estimada da BMP-2 natural, encontrada no osso. ${ }^{5}$

A molécula de rhBMP-2 é solúvel em solução extra-celular, necessitando portanto de um carreador (arcabouço) com as funções de liberar quantidades adequadas de material no sítio receptor, além de manter a concentração do material de forma a permitir a osteogênese. Os carreadores atualmente disponíveis incluem: membrana de colágeno reabsorvível, aloenxerto seco congelado/medular, matriz de fibrina, fumarato de polipropileno, hidroxiapatita, tricálcio fosfato, gel de matriz óssea desmineralizada, cimentos de fosfato de cálcio, copolímero de ácido polilático e poliglicólico. ${ }^{5,8,9}$

A utilização da rhBMP-2 na odontologia está indicada em casos de grandes fraturas e defeitos de
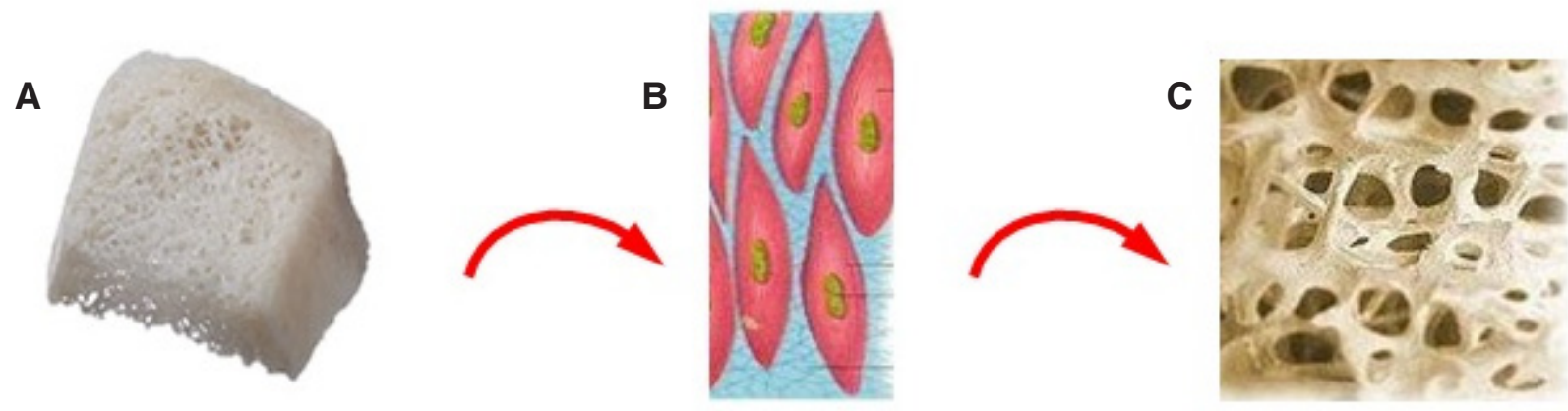

Figura 1: Formação óssea por meio das BMPs, agentes capazes de induzir a formação de osteoblastos que estão presentes na matriz óssea (A- Matriz alogênica desmineralizada, B- Tecido muscular, C- Formação óssea). 


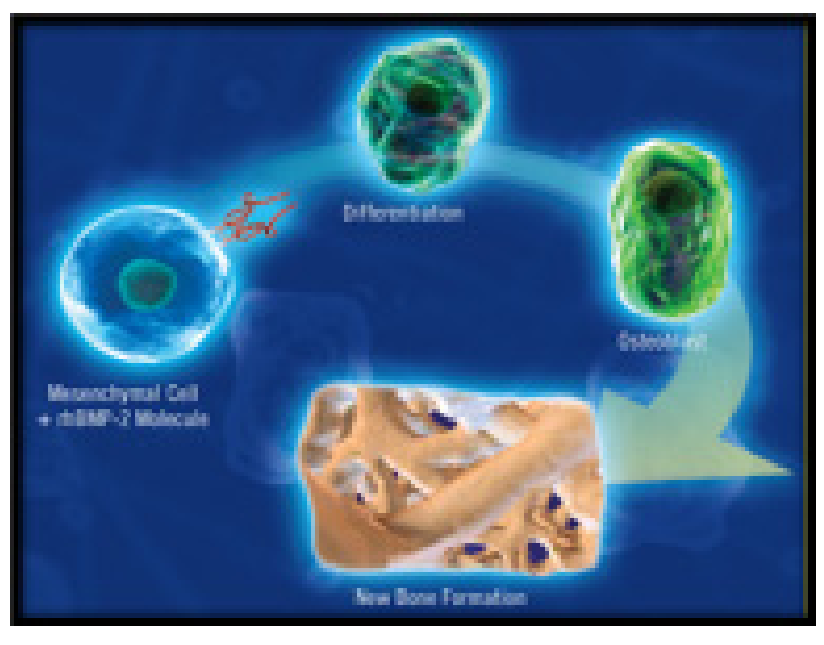

Figura 2: Formação óssea a partir de indução da molécula de rhBMP-2. (Fonte: http://www.bmp2.com.br/inf_historia.php) ${ }^{7}$

origem traumática, pós-remoção de patologias (neoplasias, cistos, tumores e osteomielites), tratamento periodontal, cirurgias para levantamento de seio maxilar e tratamento de fissuras labiopalatinas. ${ }^{10}$

O Hospital de Reabilitação de Anomalias Craniofaciais da Universidade de São Paulo (HRAC/ USP), localizado no município de Bauru, região central do estado de São Paulo, é um centro de referência nacional e internacionalmente reconhecido principalmente no tratamento reabilitador de indivíduos com fissura labiopalatina, oferecendo tratamento em todos os níveis de complexidade e nas diversas áreas que compõem a equipe para reabilitação, com uma média de 900 casos novos por ano. ${ }^{11}$

Atualmente, no HRAC/USP, para a reabilitação de pacientes com fissura labiopalatina com comprometimento do rebordo alveolar é utilizado para a reconstrução da anatomia da maxila o Indutor Ósseo INFUSE $^{\circledR}$ (Figura 3), um dispositivo que consiste de dois componentes: um recombinante humano, representado pela Proteína Morfogenética Óssea - 2 e um veículo/arcabouço para essa proteína, a esponja de colágeno absorvível. A proteína constitui uma versão de engenharia genética da proteína natural humana, normalmente encontrada em pequenas quantidades no corpo, com o propósito de estimular a formação óssea. A rhBMP-2 e excipientes são liofilizados. A esponja de colágeno absorvível é uma matriz implantável absorvente, leve, branca, maleável de rhBMP-2, sendo composta por colágeno bovino tipo I, obtido do tendão flexor profundo (Aquiles). A esponja age como um veículo (carreador) para a rhBMP-2 e funciona como uma armação para a formação do novo osso. $^{12,13}$

O enxerto alveolar com rhBMP-2 realizado em indivíduos com fissura labiopalatina tem por objetivos principais estabilizar os segmentos maxilares, restaurar a estética, promover o fechamento de fístulas, eliminar recessões mucosas, permitir a movimentação dentária por meio da terapêutica ortodôntica e possibilitar a reabilitação protética. ${ }^{14-16}$

No HRAC/USP é preconizada como época ideal para a realização do enxerto alveolar com rhBMP2 a faixa etária entre 9 e 12 anos, ou seja, antes da irrupção dos dentes caninos permanentes, em pacientes com fissuras completas, decorrentes de defeito ósseo no rebordo alveolar (Figura 4); portanto em consonância com o protocolo cirúrgico adotado pela equipe reabilitadora de Oslo. ${ }^{17}$

A técnica de enxerto alveolar com rhBMP-2 apresenta como vantagens em relação à técnica de enxerto autógeno obtido da crista ilíaca, uma menor morbidade pós-operatória, eliminação da necessidade de uma segunda área doadora, dispensa da necessidade de outro profissional da área médica, simplifi-

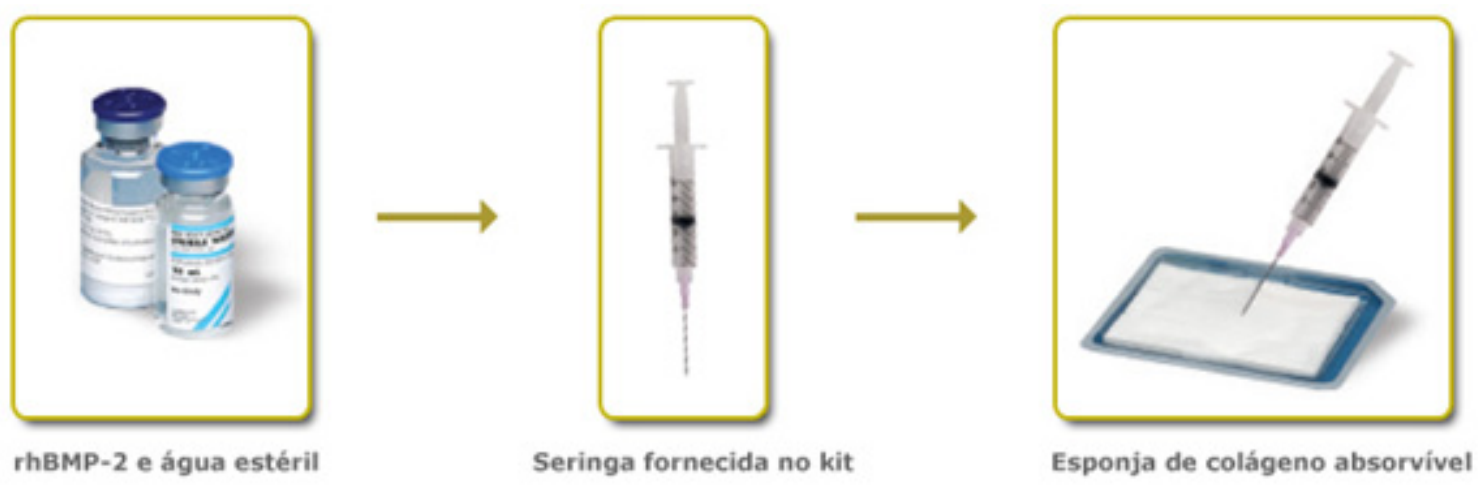

Figura 3: Kit fornecido pelo fabricante. (Fonte: http://www.bmp2.com.br/inf_historia.php) ${ }^{7}$ 


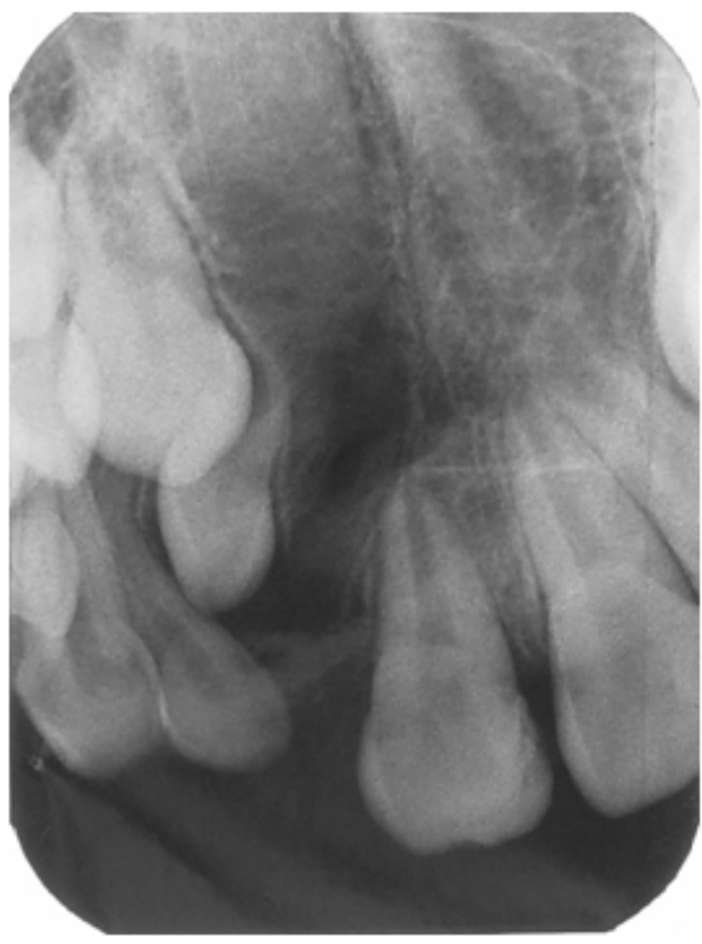

Figura 4: Defeito ósseo no rebordo alveolar.

cação do tratamento, além de isentar-se do limitante físico da quantidade de osso da área doadora, apresentando índices de sucesso semelhantes aos de enxerto autógeno de crista ilíaca. ${ }^{5}$

A técnica cirúrgica empregada pela equipe de cirurgia bucomaxilofacial do HRAC/USP para as cirurgias de enxerto alveolar com rhBMP-2 (Figuras $5 \mathrm{~A}, 5 \mathrm{~B}, 5 \mathrm{C}, 5 \mathrm{D}$ e $5 \mathrm{E}$ ) é a mesma utilizada nas cirurgias de enxerto ósseo medular de crista ilíaca.

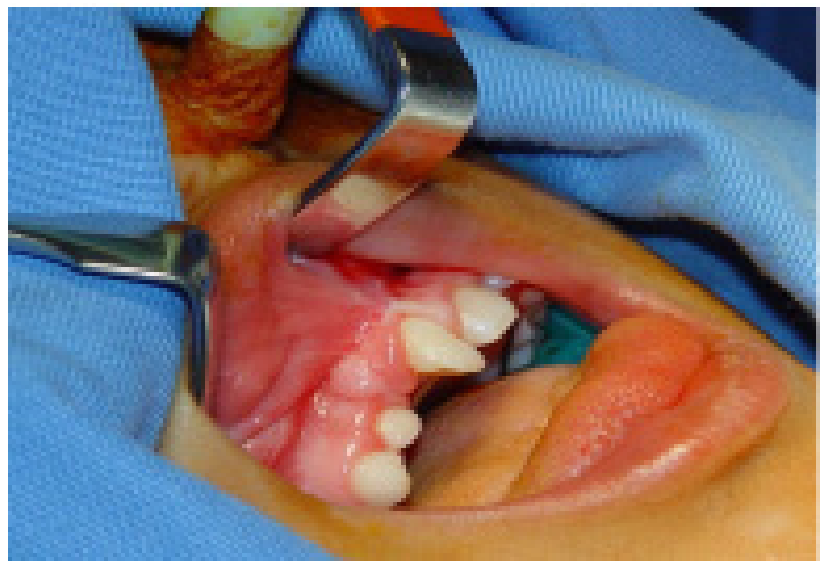

Figura 5A: Defeito anatômico localizado entre os dentes Incisivo Central superior permanente direito e Incisivo Lateral decíduo superior direito.

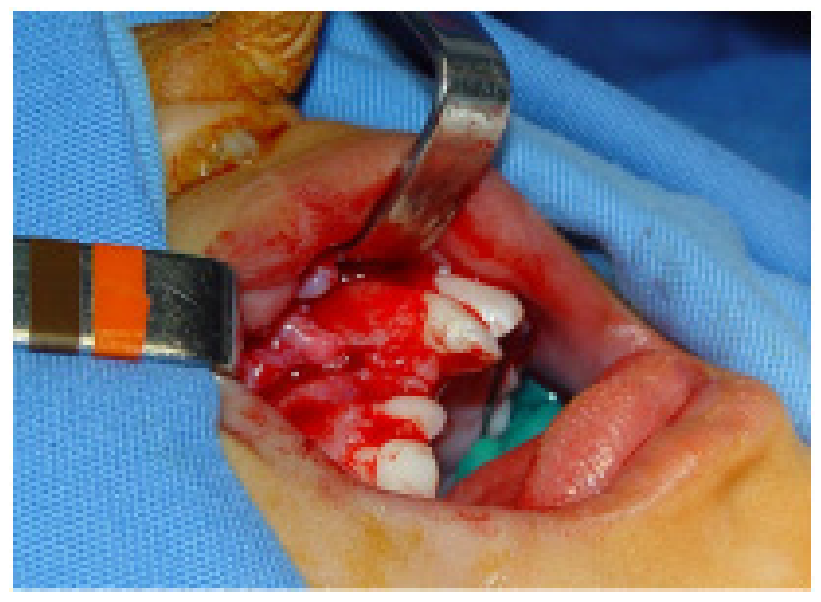

Figura 5B: Retalho dividido com incisão oblíqua a partir da mesial do dente $1^{\circ}$ Molar permanente.

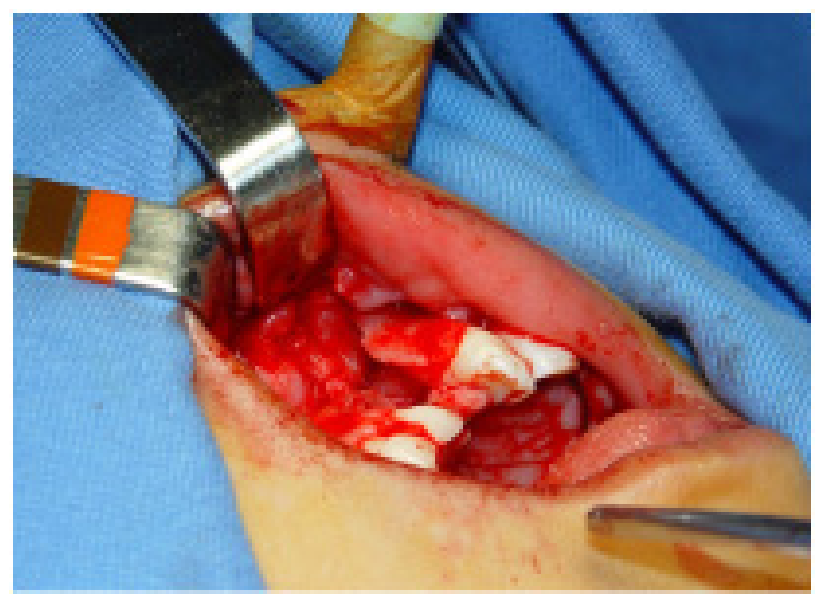

Figura 5C: Descolamento de retalho mucoperiostal, do assoalho nasal e sutura do assoalho nasal.

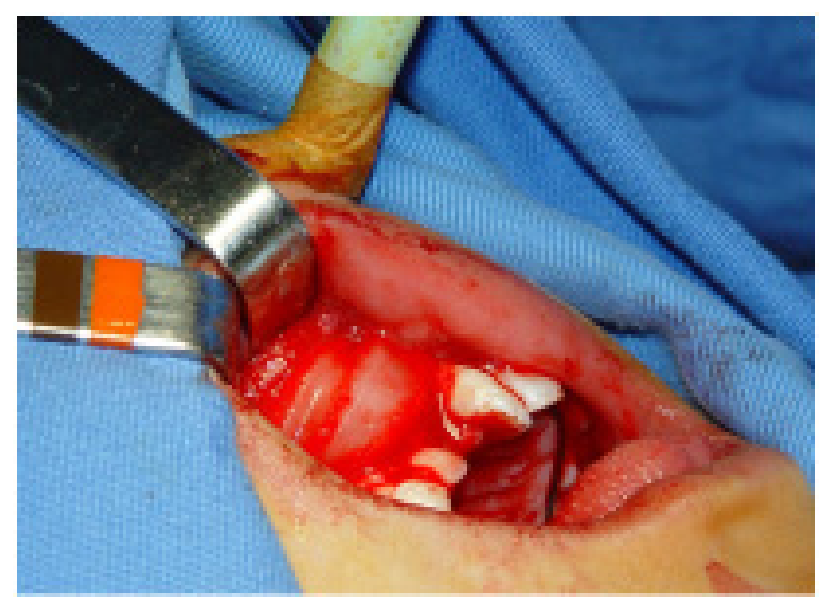

Figura 5D: Acomodação das membranas na área da fissura. 


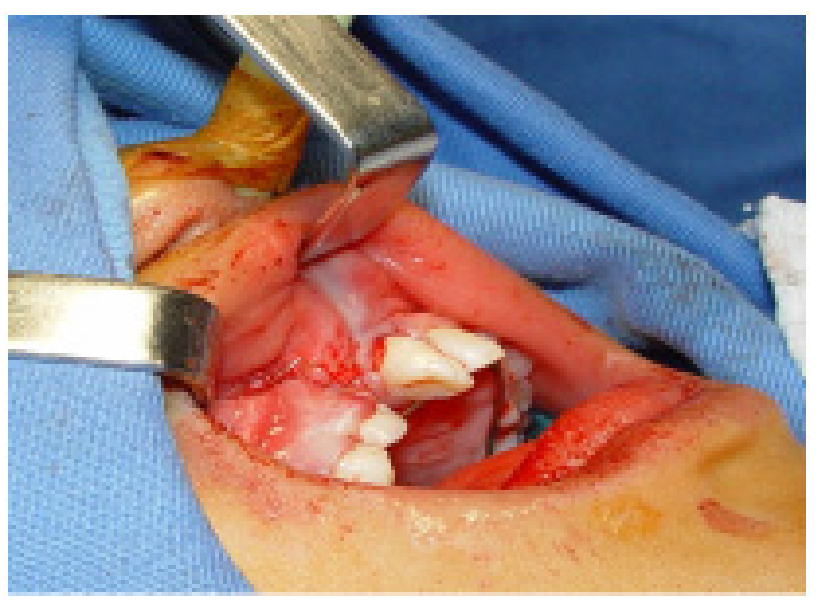

Figura 5E: $O$ retalho vestibular é reposicionado até o total recobrimento do biomaterial (rhBMP-2) e de toda extensão óssea divulsionada, sem tensão; suas bordas são debridadas sendo então realizada a sutura com pontos simples.

Contudo, apesar de suas diversas vantagens, a cirurgia de enxerto com rhBMP-2 representa um grande desafio para aplicação nos serviços públicos de saúde em função de seu elevado custo, estando disponibilizado para a venda o kit em um valor aproximado de $\mathrm{R} \$ 10.000,00$ pela empresa fabricante. Vale ressaltar ainda que um kit é utilizado em sua totalidade para um paciente com fissura completa bilateral, com possibilidade de divisão na aplicação em dois pacientes com fissura completa unilateral. ${ }^{18}$

O pós-operatório desta cirurgia é considerado crítico e de grande importância para o sucesso do tratamento, exige dos pacientes muitos cuidados tanto no que diz respeito à alimentação quanto à higienização bucal, estando estes dificultados em razão do edema pós-operatório, o qual se acentua do terceiro para o quarto dia pós-operatório, que acrescido da extensão do retalho suturado causa em muitos pacientes receio de manipular a cavidade bucal, contribuindo para uma higienização deficiente. ${ }^{18,19}$

Assim sendo, durante o período pós-operatório destes indivíduos o cuidado com a higiene bucal torna-se imprescindível de forma a evitar infecções neste período, representando um fator importante no processo saúde/doença a partir de uma concepção holística, em prevenir não somente as alterações na cavidade bucal como evitar que esses microrganismos residentes se tornem agentes complicadores do estado geral do paciente, evitando custos adicionais ao sistema público de saúde bem como contribuindo para as taxas de sucesso do procedimento realizado. ${ }^{18,19}$

\section{Conclusões}

A Bioengenharia tecidual tem se mostrado uma forte aliada nos tratamentos de ordem médica, e sobremaneira vêm recebendo destaque na odontologia. A cirurgia de enxerto alveolar com rhBMP-2 atua como um substituto do osso ilíaco na reconstituição do defeito alveolar ocasionado pela fissura, com taxas de sucesso semelhantes segundo estudos recentes. Entretanto, devem ser seguidos os cuidados inerentes à técnica cirúrgica em oferecimento de meio adequado para a molécula de rhBMP-2 assim como os cuidados pós-operatórios, garantindo a eficácia do procedimento.

É de suma importância o conhecimento dos profissionais e acadêmicos de diferentes áreas das Ciências Biológicas e da Saúde sobre as propriedades, indicações, mecanismo de ação e cuidados inerentes ao uso da proteína morfogenética óssea recombinante humana no tratamento deste grupo de indivíduos com fissura, à medida que os avanços científicos e tecnológicos por meio de pesquisas na área de biotecnologia contribuem no contexto do mundo atual cada vez mais na melhoria da qualidade de vida humana.

\section{Referênclas}

1. Oliveira CS, Nascimento $M$, Almeida Júnior ED, Crusoé $M$, Bahia P, Rosa FP. Avanços e aplicações da bioengenharia tecidual. Rev Ciênc Méd Biol. 2010; 9: 28-36.

2. Misch CE, Dietsh F. Bone-grafting materials in implant dentistry. Implant Dent. 1993; 2: 158-66.

3. Urist MR. Bone: formation by autoinduction. Science. 1965; 150: 893-9.

4. Urist MR, Strates BS. Bone morphogenetic protein. J Dent Res. 1971; 50: 1392-406.

5. Carvalho, RM. Reparo do defeito alveolar com proteína morfogenética óssea (rhBMP-2) em pacientes com fissura labiopalatina [tese]. Bauru: Hospital de Reabilitação de Anomalias Craniofaciais; 2011 [acesso 2013-07-23]. Disponível em: http:/ /www.teses.usp.br/teses/disponiveis/61/61132/tde-14022012$100227 /$.

6. Chen D, Zhao M, Mundy GR. Bone morphogenetic proteins. Growth factors. 2004; 22: 233-41.

7. BMP2. Disponível em: http://www.bmp2.com.br/inf_historia.php Acesso em: 26 de julho de 2013.

8. Kaipel M, Schützenberger S, Schultz A, Ferguson J, Slezak P, Morton TJ, et al. BMP2 but not VEGF or PDGF in fibrin matrix supports bone healing in a delayedunion rat model. J Orthop Res. 2012; 30: 1563-9.

9. Triplett RG, Nevins M, Marx RE, Spagnoli DB, Oates TW, Moy PK, et al. Pivotal, randomized, parallel evaluation of recombinant human bone morphogenetic protein-2/absorbable collagen sponge and autogenous bone graft for maxillary sinus floor augmentation. J Oral Maxillofac Surg. 2009; 67: 1947-60. 
10. Herford AS, Boyne PJ. Reconstruction of mandibular continuity defects with bone morphogenetic protein-2 (rhBMP-2). J Oral Maxillofac Surg. 2008; 66: 616-24.

11. Freitas JAS, Neves LT, Almeida ALPF, Garib DG, TrindadeSuedam IK, Yaedú RYF, et al. Rehabilitative treatment of cleft lip and palate: experience of the Hospital for Rehabilitation of Craniofacial Anomalies/USP (HRAC/USP)-Part 1: overall aspects. J Appl Oral Sci. 2012; 20: 9-15.

12. McKay WF, Peckham SM, Badura JM. A comprehensive clinical review of recombinant human bone morphogenetic protein-2 (INFUSE® Bone Graft). Int Orthop. 2007; 31: 729-34.

13. Kraiwattanapong C, Boden SD, Louis-Ugbo J, Attallah E, Barnes B, Hutton WC. Comparison of Healos/bone marrow to INFUSE (rhBMP-2/ACS) with a collagen-ceramic sponge bulking agent as graft substitutes for lumbar spine fusion. Spine. 2005; 30: 1001-7.

14. Zouhary KJ. Bone graft harvesting from distant sites: concepts and techniques. Oral Maxillofac Surg Clin North Am. 2010; 22: 301-16.
15. Herford AS, Dean JS. Complications in bone grafting. Oral Maxillofac Surg Clin North Am. 2011; 23: 433-42.

16. Krimmel M, Schuck N, Bacher M, Reinert S. Facial surface changes after cleft alveolar bone grafting. J Oral Maxillofac Surg. 2011; 69: 80-3.

17. Bergland O, Semb G, Abyholm F, Borchgrevink H, Eskeland G. Secondary bone grafting and orthodontic treatment in patients with bilateral complete clefts of the lip and palate. Ann Plast Surg. 1986; 17: 460-74.

18. Palone MRT, Silva TR, Vieira NA, Dalben GS. A importância do controle da microbiota bucal e o uso de biomaterial em cirurgias de enxerto alveolar secundário nos pacientes com fissura labiopalatina. Investigação. 2014; 13: 19-23.

19. Palone MRT, Silva TR, Vieira NA, Dalben GS. Microbiota do trato gastrintestinal de crianças com fissura envolvendo o palato. Microbiol Foco. 2013; 5: 11-18. 